\title{
Influenza infection in immunosuppressed patients: clinical characteristics, risk factors and effect of antiviral therapy
}

YaFen Liu

Peking University People's Hospital

\section{Yue Wang}

Peking University People's Hospital

\section{YuanYuan Chen}

Peking University People's Hospital

BaiYi Liu

Peking University People's Hospital

YiSi Liu

Peking University People's Hospital

\section{Ying Ji}

Peking University People's Hospital

\section{Xu Cong}

Peking University People's Hospital

Yan Gao ( $\square$ gaoyan6384@163.com )

Peking University People's Hospital https://orcid.org/0000-0002-7282-4530

\section{Research article}

Keywords: Influenza; Immunosuppression; Malignancy; Haemopoietic stem cell transplants; Antiviral therapy; Influenza vaccination

Posted Date: February 10th, 2020

DOl: https://doi.org/10.21203/rs.2.23062/v1

License: (c) (i) This work is licensed under a Creative Commons Attribution 4.0 International License. Read Full License 


\section{Abstract}

Background: Influenza infection was a vital threat to immunosuppressed patients with longer viral shedding; however, data on these populations in China are still lacking. We analyzed clinical characteristics, risk factors for admission to intensive care unit (ICU) and death, and effect of antiviral therapy in these populations.

Methods: We analyzed 73 immunosuppressed inpatients tested positive for influenza virus using reversetranscription polymerase chain reaction during the 2018-2019 influenza season. Medical data were analyzed using descriptive statistics. Univariate analysis and multivariate logistics analysis were used to identify risk factors.

Results: The most common immunosuppression type was malignancies with chemotherapy $73.9 \%$ (54/73), then hematopoietic stem cell transplantation 19.2\% (14/73). The most common presenting symptom was fever in $91.8 \%$ (67/73) patients, then cough $59.6 \%$ (34/57) and muscular soreness $35.1 \%$ (20/57). Complications and co-infections were found in 38.4\% (28/73) and 17.8\% (13/73) patients respectively, which significantly prolonged the hospital stay. Antiviral treatment after 48 hours was significantly associated with admission to ICU, mechanical ventilation and death. Combination and double dose of neuraminidase inhibitors did not significantly reduce the admission to ICU and death. $15.1 \%(11 / 73)$ patients were admitted to ICU and 8.2\% (6/73) patients died. Risk factors for admission to ICU were long symptom onset (OR 5.60, $P=0.018$ ) and co-infection with other infections (OR 68.66, $P=0.019)$, and presence of dyspnea was independently associated with death (OR 48.00, $P=0.003$ ) through multivariate logistics analysis. Seasonal influenza vaccination in preceding 12 months only took up $2.7 \%(2 / 73)$.

Conclusion: Fever and other classical symptoms may be absent in immunosuppressed recipients, and conducting influenza virus detection at the first time is a good choice for early diagnosis. Antiviral treatment within 48 hours is of significance; however, patients may not benefit from combination and double dose of neuraminidase inhibitors. Immunosuppressed patients with dyspnea, long symptom onset and co-infection with other infections are of note needed, because these people have high-risk to severe cases. Inactivated influenza vaccination should be taken into account in immunosuppressed patients.

\section{Background}

Influenza infection gathered continuous attentions because of its significant morbidity and mortality worldwide. Recently a modelling study estimated about 290 000-650 000 seasonal influenza-associated respiratory deaths each year globally [1]. While a study from China estimated that 88100 influenzaassociated excess respiratory deaths occurred in China annually [2]. Immunosuppressed patients such as patients with malignancies and chemotherapy, haemopoietic stem cell transplants (HSCT), solid-organ transplants (SOT), patients on chronic hemodialysis, and patients receiving systemic corticosteroids 
increased year by year due to medical advances [3, 4]. Compared with the immunocompetent patients, influenza infection in immunosuppressed patients had more morbidity and mortality, longer viral shedding, more frequent complications, and more antiviral resistance, increasing the potential for nosocomial transmission [3, 5-9].

Previous studies abroad most focused on influenza infection in patients with HSCT and SOT, paying less attentions to other types of immunosuppression [10-12], while investigations of outcome from influenza virus infection in immunosuppressed patients in China are still lacking. Neuraminidase inhibitors such as oseltamivir and peramivir were mainstay of antiviral therapy, previous study suggested high doses and long duration of antiviral treatment for patients who were immunocompromised [13]; however, specific data on effect of antiviral therapy in immunosuppressed patients in China are scarce. Furthermore, influenza vaccine responses in immunosuppressed populations were uncertain [3], in this study we tried to obtain the vaccination data and review the literatures on influenza vaccination strategies in immunosuppressed patients.

We did a study of influenza infection in immunosuppressed inpatients, analyzed the clinical characteristics, established risk factors for admission to intensive care unit (ICU) and death, estimated the efficacy of available antiviral drugs, and tried to know the influenza vaccination situation in these populations.

\section{Materials And Methods}

\section{Patients and study design}

During the 2018-2019 influenza season (November to the following April), a total of 23343 nasal swab specimens were obtained from influenza-like illness patients of outpatient and inpatient in Peking University People's Hospital (PKUPH), a national influenza surveillance sentinel unit, at which at least 100,000 inpatients from all over China are seen annually. Influenza A or/and B viruses were screened positive by using colloidal gold method in 4783 samples, including 140 inpatients. There were 73 immunosuppressed populations in these 140 inpatients, who were enrolled in our study, and these 73 inpatients' samples were immediately placed in virus transport media tubes and were stored at $-80^{\circ} \mathrm{C}$ within 24 hours until analyzed. Immunocompromised populations were defined as patients with HIV infection, recipients of solid-organ transplants, recipients of haemopoietic stem cell transplants, patients with malignancies and chemotherapy, patients on chronic hemodialysis, and patients receiving systemic corticosteroids [3]. Influenza infections were defined as samples detected positive by using reversetranscription polymerase chain reaction (RT-PCR) method [14].

\section{Data Collections}

Data on demographic factors (age, sex, type of immunosuppression, comorbidity, smoking, rejection in preceding 3 months, interleukin-2 receptor antagonists in preceding 6 months, monoclonal antibody in 
preceding 6 months, application of corticosteroids in preceding 3 months, seasonal influenza vaccination in preceding 12 months, application of neuraminidase inhibitors before admission), clinical presentation and complications (fever, sore throat, rhinorrhea, cough, headache, muscular soreness, dyspnea, gastrointestinal symptoms, altered mental status, symptom onset, co-infection with other infections, complications, antiviral treatment, admission to the intensive care unit, mechanical ventilation, virus detection turned negative days, death) and laboratory test results [white blood cell (WBC) counts, neutrophil, lymphocyte, platelets, alanine aminotransferase, aspartate aminotransferase, albumin, lactate dehydrogenase, creatine kinase, blood creatinine, $\mathrm{FiO}_{2}$, lactic acid, erythrocyte sedimentation rate, $\mathrm{C}$ reactive protein] were collected through the electronic medical record system of PKUPH for patients meeting the inclusion criteria. The comorbidity included diabetes, coronary heart disease, cardiac insufficiency, cerebrovascular disease, chronic nephropathy, chronic hepatopathy, and chronic lung disease based on specialist opinion. Laboratory tests were obtained from a nationally accredited laboratory.

\section{Rna Extraction And Verifying The Virus Using Rt-pcr}

RNA was extracted from samples using the QIAamp Viral RNA Mini Kit (Cat. No.52904, Qiagen, Hilden, Germany), and the extracted RNA was used as template to perform the RT-PCR with a commercial kit (Cat. No.18080051, Invitrogen, Carlsbad, CA, USA). Total RNA (8 $\mu \mathrm{l})$, universal primer 5'-AGCAAAAGCAGG$3^{\prime}(4 \mu \mathrm{l})$ and $10 \mathrm{mM}$ dNTP $(1 \mu \mathrm{l})$ were added to an RT tube on ice, incubated at $65^{\circ} \mathrm{C}$ for $5 \mathrm{~min}$ and then chilled on ice again for at least $1 \mathrm{~min}$. Thereafter, $10 \times \mathrm{RT}$ buffer $(2 \mu \mathrm{l}), 25 \mathrm{mM} \mathrm{MgCl}_{2}(4 \mu \mathrm{l}), 0.1 \mathrm{M}$ DTT $(2 \mu \mathrm{l}), \mathrm{RNaseOUT}^{\mathrm{TM}}(1 \mu \mathrm{l}$ of $40 \mathrm{U} / \mu \mathrm{L})$ and SuperScript ${ }^{\circledR}$ III reverse transcriptase $(1 \mu \mathrm{l}$ of $200 \mathrm{U} / \mu \mathrm{L})$ were added into the tube, which was then incubated at $50^{\circ} \mathrm{C}$ for $50 \mathrm{~min}$, followed by $85^{\circ} \mathrm{C}$ for $5 \mathrm{~min} .1 \mu \mathrm{l}$ of RNase $\mathrm{H}$ was added into each tube and the tubes were then incubated for $20 \mathrm{~min}$ at $37^{\circ} \mathrm{C}$ after chilling on ice and brief centrifugation. We verified the virus using PCR with high-fidelity thermostable DNA polymerase (Cat. No.11304011, Invitrogen) with specific primers as follows: forward primer (5'ACATTCGAAGCAACTGGAAA-3' and 5'- ACCCTCAGTGTGATGGCTTCCAAA-3'), reverse primer (5'GTRTTRCAATCGTGGACTGG-3' and 5'- TAAGGGAGGCATAATCCGGCACAT-3') for influenza A(H1N1)pdm09 and H3N2; forward primer (5'- AGACCAGAGGGAAACTATGCCC-3'), and reverse primer (5'TCCGGATGTAACAGGTCTGACTT-3') for influenza B viruses. The PCR amplification system included the cDNA template $(4 \mu \mathrm{l})$, autoclaved, distilled water $(12.1 \mu \mathrm{l}), 10 \mathrm{X}$ High Fidelity PCR Buffer $(2 \mu \mathrm{l}), 50 \mathrm{mM}$ $\mathrm{MgSO}_{4}(0.6 \mu \mathrm{l}), 10 \mathrm{mM}$ dNTP Mix $(0.4 \mu \mathrm{l}), 10 \mu \mathrm{M}$ forward primer $(0.4 \mu \mathrm{l}), 10 \mu \mathrm{M}$ reverse primer $(0.4 \mu \mathrm{l})$, and Platinum ${ }^{\circledR}$ Taq DNA Polymerase High Fidelity $(0.1 \mu \mathrm{l}$ of $5 \mathrm{U} / \mu \mathrm{L})$. The PCR conditions were: $94^{\circ} \mathrm{C}$ for $3 \mathrm{~min}$, followed by $35 \mathrm{cycles}$ of $94^{\circ} \mathrm{C}$ for $0.5 \mathrm{~min}, 55^{\circ} \mathrm{C}$ for $0.5 \mathrm{~min}$ and $72^{\circ} \mathrm{C}$ for $1.5 \mathrm{~min}$, with extension at $72{ }^{\circ} \mathrm{C}$ for $7 \mathrm{~min}$. The PCR products were identified through the method of electrophoresis.

\section{Statistical analysis}

All statistical analyses were performed using SPSS statistical software version 22.0 (SPSS Inc., Chicago, IL, USA). Categorical variables were expressed as counts (percentage) and compared using the $\chi^{2}$ test, 
while continuous variables were as means \pm SD or median (interquartile range) and compared using the independent samples t-test. Univariate analysis and multivariate logistics analysis were used to identify risk factors for admission to the intensive care unit and death. The removal probability for multivariate stepwise logistic regression analysis was 0.10 . $P<0.05$ was considered to be statistically significant.

\section{Results}

\section{Epidemics characteristics of study patients}

A total of 73 immunosuppressed inpatients tested positive for influenza virus using colloidal gold method were enrolled in our study. These samples were verified and classified using RT-PCR (50 influenza A viruses, and 23 influenza B viruses). Weekly distribution of immunosuppressed and immunocompetent inpatients with influenza infections in PKUPH during November 2018 to April 2019 was shown in Fig. 1. Compared with positive rate of influenza from Chinese Center for Disease Control and Prevention in northern China, which data mainly from the outpatients, we could see that influenza symptom onset of outpatients was earlier than inpatients; however, inpatients peaked earlier, especially in immunosuppressed patients.

\section{Clinical Characteristics Of Study Patients}

From the Table 1, we could see that the most common immunosuppression type was malignancies with chemotherapy $73.9 \%$ (54/73), then hematopoietic stem cell transplantation $19.2 \%$ (14/73), autoimmune disorders with immunosuppressive therapy $5.5 \%$ (4/73), and solid-organ transplantation only accounted for $1.4 \%(1 / 73)$. Malignancies almost included all types of tumors, such as lung cancer, bone tumor, hepatoma, cholangiocarcinoma, gastrointestinal tumor, urologic tumor, gynecologic tumor, leukemia, lymphoma, other hematologic tumors, breast cancer, thyroid cancer, neuroendocrine neoplasm. Among these patients with malignancies, one patient had both breast cancer and leukemia, and two had both gynecologic tumor and leukemia. The most common transplant type was hematopoietic stem cell transplantation, one case solid-organ transplantation was kidney transplantation. The median time of symptom onset after transplant was 11 months (range 5-73 months). 46.7\% (7/15) of transplant patients had rejection in preceding 3 months. Application of corticosteroids in preceding 3 months represented the proportion with $19.2 \%$ (14/73). Seasonal influenza vaccination in preceding 12 months only took up $2.7 \%(2 / 73)$, and these two patients had no complications and co-infections, and fever disappeared within 48 hours after antiviral treatment. 


\begin{tabular}{|ll|}
\hline \multicolumn{2}{|l|}{ Table 1 Demographics of immunosuppressed patients with influenza infections } \\
\hline & Findings ( $\mathrm{n}=73)$ \\
\hline Age, median years (range) & $54(4-85)$ \\
\hline Male sex (\%) & $35(47.9)$ \\
\hline Type of immunosuppression & \\
\hline Malignancies and chemotherapy (\%) & $54(73.9)$ \\
\hline Hematopoietic stem cell transplantation (\%) & $14(19.2)$ \\
\hline Solid-organ transplantation (\%) & $1(1.4)$ \\
\hline Autoimmune disorders and immunosuppressive therapy (\%) & $4(5.5)$ \\
\hline Comorbidity & \\
\hline Diabetes (\%) & $9(12.3)$ \\
\hline Coronary heart disease (\%) & $3(4.1)$ \\
\hline Cardiac insufficiency (\%) & $1(1.4)$ \\
\hline Cerebrovascular disease (\%) & $6(8.2)$ \\
\hline Chronic nephropathy (\%) & $6(8.2)$ \\
\hline Chronic hepatopathy (\%) & $2(2.7)$ \\
\hline Chronic lung disease (\%) & $4(5.5)$ \\
\hline Smoking (\%) & $16(21.9)$ \\
\hline Rejection in preceding 3 months (\%) & $7 / 15(46.7)$ \\
\hline Interleukin-2 receptor antagonists in preceding 6 months (\%) & $4(5.5)$ \\
\hline Monoclonal antibody in preceding 6 months (\%) & $1(1.4)$ \\
\hline Application of corticosteroids in preceding 3 months (\%) & $14(19.2)$ \\
\hline Seasonal influenza vaccination in preceding 12 months (\%) & $2(2.7)$ \\
\hline Application of neuraminidase inhibitors before admission & $1(1.4)$ \\
\hline
\end{tabular}

The most common presenting symptom was fever in $91.8 \%$ (67/73) patients, then cough $59.6 \%(34 / 57)$, muscular soreness $35.1 \%(20 / 57)$, sore throat $19.3 \%$ (11/57), headache $17.9 \%(10 / 56)$, rhinorrhea $17.9 \%$ (10/56), gastrointestinal symptoms $14.3 \%$ (8/56), dyspnea $12.1 \%(7 / 58)$, altered mental status $5.4 \%$ $(3 / 56)$. (Table 2) 
From the Table 2, we also could see that the symptom onset was 24 hours (range 6-360 hours). $38.4 \%$ (28/73) patients were presence of complications. Imaging (chest radiograph or CT) data were available for 67 of 73 patients, and $40.3 \%$ (27/67) patients had imaging findings consistent with pneumonia. As to other complications, acute respiratory distress syndrome accounted for $9.6 \%(7 / 73)$, shock for $4.1 \%$ (3/73), acute kidney injury for $2.7 \%(2 / 73)$, and viral encephalitis for $1.4 \%(1 / 73)$. 


\section{Table 2 Clinical presentation and complications of immunosuppressed patients with influenza infections}

Findings

Fever (\%)

Sore throat (\%)

Rhinorrhea (\%)

Cough (\%)

Headache (\%)

Muscular soreness (\%)

Dyspnea (\%)

Gastrointestinal symptoms (\%)

Altered mental status (\%)

Symptom onset, hours (range)

Co-infection with other infections (\%)

Complications

Pneumonia on chest radiograph or CT scan (\%)

Acute Respiratory Distress Syndrome (\%)

Shock (\%)

Acute Kidney Injury (\%)

Viral encephalitis (\%)

Antiviral treatment (\%)

Antiviral treatment within 48 hours (\%)

Antiviral treatment after 48 hours (\%)

Oseltamivir (\%)

Peramivir (\%)

Alternate Oseltamivir and Peramivir (\%)

Combination of oseltamivir and peramivir (\%)

Admission to the intensive care unit (\%)

Mechanical ventilation (\%)
67/73(91.8)

$11 / 57(19.3)$

10/56(17.9)

$34 / 57(59.6)$

10/56(17.9)

20/57(35.1)

$7 / 58(12.1)$

8/56(14.3)

$3 / 56(5.4)$

24(6-360)

13/73(17.8)

28/73(38.4)

$27 / 67(40.3)$

7/73(9.6)

3/73(4.1)

2/73(2.7)

1/73(1.4)

68/73(93.2)

57/73(78.1)

11/73(15.1)

53/68(77.9)

7/68(10.3)

2/68(2.9)

6/68(8.8)

11/73(15.1)

9/73(12.3) 


\section{Table 2 Clinical presentation and complications of immunosuppressed patients with influenza infections}

Virus detection turned negative, days (range)*

Hospital stay, days (range)

Death $(\%)$
$3(1-11)$

15(1-90)

$6 / 73(8.2)$

*Data is available only for 34 patients

As shown in Table 3, blood routine was characterized by lymphopenia in immunosuppressed populations with influenza infections. Erythrocyte sedimentation rate and C-reactive protein could be a little higher than normal. Albumin was usually lower than normal.

\begin{tabular}{|ll|}
\hline Table 3 Laboratory test results of immunosuppressed patients with influenza infections \\
\hline WBC* counts $\left(\times 10^{9} / \mathrm{L}\right)$ & Findings \\
\hline Neutrophil $(\%)$ & $4.8(0.2-64.7)$ \\
\hline Neutrophil $\left(\times 10^{9} / \mathrm{L}\right)$ & $70.6(0.0-96.4)$ \\
\hline Lymphocyte $(\%)$ & $3.5(0.0-63.7)$ \\
\hline Lymphocyte $\left(\times 10^{9} / \mathrm{L}\right)$ & $16.2(1.4-97.4)$ \\
\hline Platelets $\left(\times 10^{9} / \mathrm{L}\right)$ & $0.7(0.0-58.1)$ \\
\hline Alanine aminotransferase $(\mathrm{U} / \mathrm{L})$ & $117.0(8.0-429.0)$ \\
\hline Aspartate aminotransferase $(\mathrm{U} / \mathrm{L})$ & $16.0(2.0-279.0)$ \\
\hline Albumin $(\mathrm{g} / \mathrm{L})$ & $20.0(11.0-118.0)$ \\
\hline Lactate dehydrogenase $(\mathrm{U} / \mathrm{L})$ & $33.9(22.4-48.7)$ \\
\hline Creatine kinase $(\mathrm{U} / \mathrm{L})$ & $186.0(96.0-890.0)$ \\
\hline Blood creatinine $(\mu \mathrm{mmol} / \mathrm{L})$ & $29.0(6.0-725.0)$ \\
\hline FiO ${ }_{2}(\mathrm{mmHg})$ & $58.0(22.0-178.0)$ \\
\hline Lactic acid & $232.4(97.5-512.6)$ \\
\hline Erythrocyte sedimentation rate $(\mathrm{mm} / \mathrm{h})$ & $1.3(0.4-2.5)$ \\
\hline C-reactive protein $(\mathrm{mg} / \mathrm{L})$ & $22.0(9.0-123.0)$ \\
\hline$*$ WBC: white blood cell & $27.5(0.5-416.9)$ \\
\hline
\end{tabular}


Co-infections were found in 17.8\% (13/73) patients, and pathogens distribution were shown in Table 4. Bacterial pathogens were identified from blood, qualified sputum, or ascites in $8(11.0 \%)$ of 73 patients, which included Escherichia coli, Klebsiella pneumoniae, Pseudomonas aeruginosa, Stenotrophomonas maltophilia, Enterococcus faecium, Streptococcus. Two patients had fungal infections (both were Aspergillus spp.), the hospital stays of which were 90 and 51 days respectively (the latter died). Cytomegalovirus and Epstein-Barr virus viremia were detected in 4 (5.5\%) and 2 (2.7\%) of 73 patients, while one Herpes simplex virus and one Parainfluenza virus were detected.

\section{Table 4 Pathogens distribution of co-infection with other infections}

$\begin{array}{llll}\begin{array}{l}\text { Patient } \\ \text { No. }\end{array} & \text { Bacteria (Sample type) } & \text { Fungi (Sample type) } & \begin{array}{l}\text { Viruses (Blood nucl } \\ \text { acid) }\end{array} \\ 7 & \text { Enterococcus faecium (Blood) } & \\ 12 & & \begin{array}{l}\text { Aspergillus spp. } \\ \text { (BAL + GM + chest }\end{array} & \text { Cytomegalovirus } \\ & \text { CT) } & \end{array}$

14 Stenotrophomonas maltophilia (Qualified sputum)

$20 \quad$ Escherichia coli and Enterococcus faecium (Ascites)
23
Aspergillus spp.
Parainfluenza virus
(BAL + GM + chest and Cytomegalovirus
CT)

\begin{tabular}{|ll}
26 & Streptococcus (Qualified sputum) \\
36 & $\begin{array}{l}\text { Escherichia coli, Klebsiella pneumoniae } \\
\text { and Enterococcus faecium (Ascites) }\end{array}$ \\
44 & Escherichia coli (Blood)
\end{tabular}

62

Cytomegalovirus

63

Cytomegalovirus and Epstein-Barr virus

$64 \quad$ Klebsiella pneumoniae and

Pseudomonas aeruginosa (Blood)

Epstein-Barr virus

66

Herpes simplex virus

69

Escherichia coli (Blood)

BAL: bronchoalveolar lavage fluid

GM: galactomannan 
The median day of hospital stay was 15 days (range 1-90 days), and it significantly associated with organ transplantation, application of corticosteroids in preceding 3 months, complications, and coinfection with other infections (Fig. 2).

\section{Effect Of Antiviral Therapy}

$68(93.2 \%)$ of 73 patients received antiviral treatment as follows, $77.9 \%$ (53/68) were given oseltamivir, $10.3 \%$ (7/68) were given intravenous peramivir, $2.9 \%$ (2/68) received oseltamivir and peramivir alternately, and $8.8 \%(6 / 68)$ were given oseltamivir with peramivir. Combination of oseltamivir and peramivir was not significantly associated with admission to the ICU and death through the $\chi^{2}$ test (Pख0.05).

95.6\% (65/68) patients received standard dosing antiviral treatment that adult patients received oseltamivir at the equivalent of $75 \mathrm{mg}$ twice or peramivir $300 \mathrm{mg}$ once per day, and children received standard dosing according to weight, while 4.5\% (3/68) patients received double dose. Double dose of neuraminidase inhibitors was also not significantly associated with admission to the ICU and death through the $\chi^{2}$ test $(\mathrm{P} \otimes 0.05)$.

Median duration of antiviral treatment was 6 days (range 1-32). Antiviral treatment began within 48 hours of symptom onset in 83.8\% (57/68), and greater than 48 hours in $16.2 \%(11 / 68)$. Antiviral treatment after 48 hours was significantly associated with admission to the ICU, mechanical ventilation and death through the $\chi^{2}$ test $(P<0.05)$. Median day of virus detection turned negative was 3 days (range 1-11); however, our data was available only for 34 patients, because some mild illness did not recheck and some severe illness lasted positive persistently even to death. Analyzed these 34 patients' data, days of virus detection turned negative were associated with complications and antiviral treatment after 48 hours (Fig. 3).

\section{Risk Factors For Admission To Icu}

In our study $15.1 \%(11 / 73)$ patients were admitted to the ICU, and we performed univariate analysis of all variables in Table 1, 2, and 3 for exploring factors with $P<0.05$ associated with admission to the ICU, namely presence of organ transplantation (OR 7.07), diabetes (OR 6.51), application of corticosteroids in preceding 3 months (OR 8.10), long symptom onset (OR 2.66), dyspnea (OR 29.38), altered mental status (OR 16.00), co-infection with other infections (OR 8.91), complications (OR 9.00), and antiviral treatment after 48 hours (OR 10.31). In multivariate logistic regression model, long symptom onset (OR $5.60,95 \% \mathrm{Cl}$ $1.34-23.38, \mathrm{P}=0.018)$ and co-infection with other infections ( $\mathrm{OR} 68.66,95 \% \mathrm{Cl} 1.98-2384.50, \mathrm{P}=0.019)$ were independently associated with increased risks of admission to ICU. (Table 5) 


\section{Table 5 Risks for admission to ICU of immunosuppressed patients with influenza infections in Logistics analysis}

\begin{tabular}{|c|c|c|c|c|}
\hline Variables & Odds Ratio & \multicolumn{2}{|c|}{$(95 \% \mathrm{Cl})$} & $\mathrm{P}$ \\
\hline Organ transplantation & 7.07 & 1.78 & 28.12 & 0.006 \\
\hline Diabetes & 6.51 & 1.41 & 30.12 & 0.016 \\
\hline Application of corticosteroids in preceding 3 months & 8.10 & 2.00 & 32.85 & 0.003 \\
\hline Symptom onset & 2.66 & 1.33 & 5.34 & 0.006 \\
\hline Dyspnea & 29.38 & 4.26 & 202.71 & 0.001 \\
\hline Altered mental status & 16.00 & 1.25 & 204.11 & 0.033 \\
\hline Co-infection with other infections & 8.91 & 2.14 & 30.07 & 0.003 \\
\hline Complications & 9.00 & 1.77 & 45.85 & 0.008 \\
\hline Antiviral treatment after $48 \mathrm{~h}$ & 10.31 & 2.50 & 42.52 & 0.001 \\
\hline Variables & Odds Ratio & \multicolumn{2}{|c|}{$(95 \% \mathrm{Cl})$} & $P$ \\
\hline Symptom onset & 5.60 & 1.34 & 23.38 & 0.018 \\
\hline Co-infection with other infections & 68.66 & 1.98 & 2384.50 & 0.019 \\
\hline
\end{tabular}

\section{Risk Factors For Death}

In our study 8.2\% (6/73) patients died, and we performed univariate analysis of all variables in Table 1, 2, and 3 for exploring factors with $\mathrm{P}<0.05$ associated with death, namely presence of organ transplantation (OR 28.50), application of corticosteroids in preceding 3 months (OR 11.40), dyspnea (OR 66.67), altered mental status (OR 52.00), co-infection with other infections (OR 12.22), shock (OR 32.50), antiviral treatment after 48 hours (OR 25.46), and admission to ICU (OR 50.83). In multivariate logistic regression model, presence of dyspnea was independently associated with increased risks of death (OR 48.00,95\% $\mathrm{Cl} 3.76-612.33, \mathrm{P}=0.003)$. (Table 6) 


\begin{tabular}{|c|c|c|c|c|}
\hline \multirow{2}{*}{$\begin{array}{l}\text { Variables } \\
\text { Organ transplantation }\end{array}$} & \multirow{2}{*}{$\begin{array}{l}\text { Odds Ratio } \\
28.50\end{array}$} & \multicolumn{2}{|c|}{$(95 \% \mathrm{Cl})$} & \multirow{2}{*}{$\begin{array}{l}P \\
0.004\end{array}$} \\
\hline & & 3.01 & 270.33 & \\
\hline Application of corticosteroids in preceding 3 months & 11.40 & 1.84 & 70.75 & 0.009 \\
\hline Dyspnea & 66.67 & 5.57 & 797.49 & 0.001 \\
\hline Altered mental status & 52.00 & 3.21 & 842.48 & 0.005 \\
\hline Co-infection with other infections & 12.22 & 1.95 & 76.79 & 0.008 \\
\hline Shock & 32.50 & 2.40 & 439.40 & 0.009 \\
\hline Antiviral treatment after $48 \mathrm{~h}$ & 25.46 & 2.70 & 239.64 & 0.005 \\
\hline Admission to the intensive care unit & 50.83 & 5.07 & 509.56 & 0.001 \\
\hline Variables & Odds Ratio & \multicolumn{2}{|c|}{$(95 \% \mathrm{Cl})$} & $\mathrm{P}$ \\
\hline Dyspnea & 48.00 & 3.76 & 612.33 & 0.003 \\
\hline
\end{tabular}

\section{Discussion}

In this study, half of inpatients with influenza infection in PKUPH were immunosuppressed cases. Compared with the outpatients and immunocompetent inpatients, immunosuppressed patients peaked earliest, which indicated their susceptibility to influenza infection (Fig. 1). Previous studies most focused on influenza infection in patients with HSCT and SOT; however, more attentions have been paid to other types of immunosuppression in recent years $[4,15,16]$, the most common immunosuppression type in this study was malignancies with chemotherapy accounted for $73.9 \%$, even with two different types of tumors. HSCT was the most common transplant type, the median time of symptom onset after transplant was 11 months, nearly half of whom had rejection in preceding 3 months.

The common presenting symptoms of influenza infection in immunosuppressed patients were variable in different studies; however, most patients exhibited fever and cough $[5,17]$. It was worth noting that in immunosuppressed recipients, fever and other classical symptoms such as cough, muscular soreness, sore throat, headache, rhinorrhea may be absent, instead of gastrointestinal symptoms, dyspnea and altered mental status $[5,18]$. As to complications, pneumonia was the most common $(40.3 \%)$, consistent with previous literature from $32-56 \%[11,15,17]$; however, other relatively rare complications such as acute respiratory distress syndrome, shock, acute kidney injury, and viral encephalitis were also should be taken seriously. Co-infections with bacterial, fungal, and other viral pathogens were found in $17.8 \%$ patients, which have been reported in previous studies $[3,15,17]$. Co-infection with other infections significantly prolonged the hospital stay and increased risks of admission to ICU, especially with Aspergillus spp. infection. The hospital stays of two patients with Aspergillus spp. were 90 and 51 days respectively (the latter died). Dunbar et al. discussed influenza and invasive aspergillosis in 
immunocompromised patients, and summarized probable mechanisms for influenza and aspergillus mixed infections were disruption of bronchial mucosal barrier and phagocytosis, T-cell dysfunction and apoptosis, and neuraminidase inhibitors use and so on [19]. Laboratory test results of influenza infection in immunosuppressed patients were characterized as lymphopenia, a little higher erythrocyte sedimentation rate and C-reactive protein, and lower albumin than normal, and partial results were consistent with previous studies, furthermore, several studies point that lymphopenia was a risk factor for severe cases [20-22]. Based on the clinical characteristics above, greater consideration should be given to early identification of influenza infection in immunosuppressed patients, conducting influenza virus detection at the first time.

We described the use and effect of neuraminidase inhibitors in these people, and found antiviral treatment after 48 hours was significantly associated with admission to the ICU, mechanical ventilation and death, according with guideline suggestion clinicians should start antiviral treatment as soon as possible for immunocompromised patients [16, 23, 24]. Immunocompromised patients were susceptible to suffering from antiviral drug resistance due to prolonged viral shedding $[17,25,26]$, which also contributed to more influenza-related death and nosocomial transmission [12, 27, 28]. Previous studies recommended higher doses and/or prolonged courses of antiviral therapy [7]. In our study combination and double dose of neuraminidase inhibitors did not significantly reduce the risk for admission to the ICU and death. Median duration of treatment was 6 days (range 1-32) in our study, and longer duration of antiviral treatment maybe more benefit for immunocompromised patients, as influenza viral replication was often protracted [14]. Data on virus detection turned negative was not available for more than half, and some severe illness lasted positive persistently even to death. We should pay attention to complications and early antiviral treatment by analyzing these 34 patients' data.

In our study $15.1 \%$ patients were admitted to the ICU and mortality rate was $8.2 \%$, similar or even higher than some other large sample studies $[11,15,16]$. Presence of organ transplantation, dyspnea, altered mental status, application of corticosteroids in preceding 3 months, co-infection with other infections, and antiviral treatment after 48 hours were both associated with admission to the ICU and death in univariate analysis. Furthermore diabetes, long symptom onset, and complications were risk factors for admission to the ICU. In multivariate logistics analysis risk factors for admission to ICU were long symptom onset and co-infection with other infections, and presence of dyspnea was independently associated with increased risks of death. Part of above risk factors have been reported in previous literatures [11, 15, 29-31], and some were the first reported; however, all analyses reminded us of identification of patients at risk of a severe course. Corticosteroids therapy may decrease inflammation, but at the cost of longer duration of viral shedding [30, 32-34].

Recently Chinese scholars pointed out that absence of an active immunization program could explain influenza-associated mortality was higher than other countries with higher vaccination coverage, in our study seasonal influenza vaccination rate was lower than $3 \%$. The suggestions of influenza vaccines depended on types of immunosuppression [3]. There were evidences that HSCT population could benefit from vaccination [35-38], and the latest recommendation was to start inactivated vaccines from 3

Page $14 / 22$ 
months after transplant [39]. However, a systematic review showed that seasonal inactivated influenza vaccine remained suboptimal in SOT recipients [40]. No consensus guidelines on influenza vaccination for patients with malignancies, but timing of vaccination was recommended more than two weeks before receiving chemotherapy or between chemotherapy cycles in order to enhance humoral responses [3].

The data obtained from our study was essential to understand outcomes of influenza infection in immunosuppressed patients, but this study had limitation that data collection was limited to one influenza season of one hospital. Therefore, further studies with a larger sample size will be needed to confirm and extend our findings.

\section{Conclusions}

Our survey of clinical characteristics, risk factors, and effect of antiviral therapy of influenza infection in immunosuppressed patients supplemented the investigations of these population in China. Malignancies with chemotherapy was the most common immunosuppression type, and more attention should be given to these people. Fever and other classical symptoms may be absent in immunosuppressed recipients, and conducting influenza virus detection at the first time is a good choice for early diagnosis. Antiviral treatment after 48 hours was significantly associated with admission to the ICU, mechanical ventilation and death. However, in our study the patients did not benefit from combination and double dose of neuraminidase inhibitors treatment. Patients with dyspnea, long symptom onset and co-infection with other infections are of note needed, because these people have high-risk to severe cases. Seasonal influenza vaccination rate in China was still low, and inactivated influenza vaccination should be taken into account in immunosuppressed patients.

\section{Declarations}

\section{Abbreviations}

ICU: Intensive care unit; HSCT: Haemopoietic stem cell transplants; SOT: Solid-organ transplants; PKUPH: Peking University People's Hospital; RT-PCR: Reverse-transcription polymerase chain reaction; WBC: white blood cell

\section{Acknowledgements}

We thank all the participants for their contributions to this study.

\section{Authors' contributions}

YFL participated in the design of the study, analyzed the data, performed the statistical analysis and drafted the manuscript. YW participated in the design of the study, collected the data, performed the statistical analysis and revised the manuscript. YYC collected and analyzed the data. BYL, YSL, YJ and $X C$ collected, transported and saved the samples and helped to perform the experiments. YG conceived 
and designed the study, coordinated the research groups and helped to modified the manuscript. All authors have read and approved the final manuscript.

\section{Funding}

This work was supported by emergency management project of National Natural Science Foundation of China (grant number 81541139) and research and development fund of Peking University People's Hospital (grant number RD 2016-14). The funders had no role in study design, data collection and analysis, decision to publish or preparation of the manuscript.

\section{Availability of data and materials}

The datasets analyzed during the current study are available from the corresponding author on reasonable request.

\section{Ethics approval and consent to participate}

This study has been carried out in accordance with the Declaration of Helsinki and was approved by the ethics committees of the Peking University People's Hospital (PKUPH, IRB No. 2016PHB100-01). Written informed consents were obtained prior to their inclusion in this study. Nasal samples and medical data were collected and analyzed anonymously.

\section{Consent for publication}

Not applicable.

\section{Competing interest}

The authors declare that they have no competing interests.

\section{Author details}

${ }^{1}$ Department of Infectious Diseases, Peking University Hepatology Institute, Peking University People's Hospital, No. 11, Xizhimen South Street, Beijing 100044, P. R. China. ${ }^{2}$ Peking University Hepatology Institute, Peking University People's Hospital, No. 11, Xizhimen South Street, Beijing 100044, P. R. China.

\section{References}

1. Iuliano AD, Roguski KM, Chang HH, Muscatello DJ, Palekar R, Tempia S, et al. Estimates of global seasonal influenza-associated respiratory mortality: a modelling study. Lancet. 2018; 391(10127): 1285-1300.

2. Li L, Liu Y, Wu P, Peng $Z$, Wang $X$, Chen $T$, et al. Influenza-associated excess respiratory mortality in China, 2010-15: a population-based study. Lancet Public Health. 2019; 4(9): e473-e481. 
3. Kunisaki KM, Janoff EN. Influenza in immunosuppressed populations: a review of infection frequency, morbidity, mortality, and vaccine responses. Lancet Infect Dis. 2009; 9(8): 493-504.

4. Di Pasquale MF, Sotgiu G, Gramegna A, Radovanovic D, Terraneo S, Reyes LF, et al. Prevalence and Etiology of Community-acquired Pneumonia in Immunocompromised Patients. Clin Infect Dis. 2019; 68(9): 1482-1493.

5. Memoli MJ, Athota R, Reed S, Czajkowski L, Bristol T, Proudfoot K, et al. The natural history of influenza infection in the severely immunocompromised vs nonimmunocompromised hosts. Clin Infect Dis. 2014; 58(2): 214-24.

6. Ison MG. Influenza prevention and treatment in transplant recipients and immunecompromised hosts. Influenza Other Respir Viruses. 2013; 7 Suppl 3: 60-6.

7. Eshaghi A, Shalhoub S, Rosenfeld P, Li A, Higgins RR, Stogios PJ, et al. Multiple influenza A (H3N2) mutations conferring resistance to neuraminidase inhibitors in a bone marrow transplant recipient. Antimicrob Agents Chemother. 2014; 58(12): 7188-97.

8. Weinstock DM, Gubareva LV, Zuccotti G. Prolonged shedding of multidrug-resistant influenza A virus in an immunocompromised patient. N Engl J Med. 2003; 348(9): 867-8.

9. Nichols WG, Guthrie KA, Corey L, Boeckh M. Influenza infections after hematopoietic stem cell transplantation: risk factors, mortality, and the effect of antiviral therapy. Clin Infect Dis. 2004; 39(9): 1300-6.

10. Reid G, Huprikar S, Patel G, Razonable RR, Mossad S, Levi M, et al. A multicenter evaluation of pandemic influenza A/H1N1 in hematopoietic stem cell transplant recipients. Transpl Infect Dis. 2013; 15(5): 487-92.

11. Kumar D, Michaels MG, Morris MI, Green M, Avery RK, Liu C, et al. Outcomes from pandemic influenza A H1N1 infection in recipients of solid-organ transplants: a multicentre cohort study. Lancet Infect Dis. 2010; 10(8): 521-6.

12. Nichols WG, Guthrie KA, Corey L, Boeckh M. Influenza infections after hematopoietic stem cell transplantation: risk factors, mortality, and the effect of antiviral therapy. Clin Infect Dis. 2004; 39(9): $1300-6$.

13. Kumar D, Morris MI, Kotton CN, Fischer SA, Michaels MG, Allen U, et al. Guidance on novel influenza A/H1N1 in solid organ transplant recipients.Am J Transplant. 2010; 10(1): 18-25.

14. Uyeki TM, Bernstein HH, Bradley JS, Englund JA, File TM, Fry AM, et al. Clinical Practice Guidelines by the Infectious Diseases Society of America: 2018 Update on Diagnosis, Treatment, Chemoprophylaxis, and Institutional Outbreak Management of Seasonal Influenzaa. Clin Infect Dis. 2019; 68(6): 895-902.

15. Hermann B, Lehners N, Brodhun M, Boden K, Hochhaus A, Kochanek M, et al. Influenza virus infections in patients with malignancies - characteristics and outcome of the season 2014/15. A survey conducted by the Infectious Diseases Working Party (AGIHO) of the German Society of Haematology and Medical Oncology (DGHO). Eur J Clin Microbiol Infect Dis. 2017; 36(3): 565-573. 
16. Collins JP, Campbell AP, Openo K, Farley MM, Cummings CN, Hill M, et al. Outcomes of immunocompromised adults hospitalized with laboratory-confirmed influenza in the United States, 2011-2015. Clin Infect Dis. 2019; pii: ciz638.

17. Tramontana AR, George B, Hurt AC, Doyle JS, Langan K, Reid AB, et al. Oseltamivir resistance in adult oncology and hematology patients infected with pandemic (H1N1) 2009 virus, Australia. Emerg Infect Dis. 2010; 16(7): 1068-75.

18. Ljungman P, de la Camara R, Perez-Bercoff L, Abecasis M, Nieto Campuzano JB, Cannata-Ortiz MJ, et al. Outcome of pandemic H1N1 infections in hematopoietic stem cell transplant recipients. Haematologica. 2011; 96(8): 1231-5.

19. Dunbar A, Schauwvlieghe A, Rijnders BJA. Influenza and Invasive Aspergillosis in Immunocompromised Patients. Clin Infect Dis. 2019; 69(11): 2037.

20. Boeckh M. The challenge of respiratory virus infections in hematopoietic cell transplant recipients. $\mathrm{Br}$ J Haematol. 2008; 143(4): 455-67.

21. Chemaly RF, Ghosh S, Bodey GP, Rohatgi N, Safdar A, Keating MJ, et al. Respiratory viral infections in adults with hematologic malignancies and human stem cell transplantation recipients: a retrospective study at a major cancer center. Medicine (Baltimore). 2006; 85(5): 278-87.

22. Apewokin S, Vyas K, Lester LK, Grazzuitti M, Haselow DT, Wolfe F, et al. Influenza a outbreak in an ambulatory stem cell transplant center. Open Forum Infect Dis. 2014; 1(2): ofu050.

23. Paulsen GC, Danziger-Isakov L. Respiratory Viral Infections in Solid Organ and Hematopoietic Stem Cell Transplantation. Clin Chest Med. 2017; 38(4): 707-726.

24. Kmeid J, Vanichanan J, Shah DP, El Chaer F, Azzi J, Ariza-Heredia EJ, et al. Outcomes of Influenza Infections in Hematopoietic Cell Transplant Recipients: Application of an Immunodeficiency Scoring Index.Biol Blood Marrow Transplant. 2016; 22(3): 542-8.

25. Chemaly RF, Shah DP, Boeckh MJ. Management of respiratory viral infections in hematopoietic cell transplant recipients and patients with hematologic malignancies. Clin Infect Dis. 2014; 59 Suppl 5: S344-51.

26. Weinstock DM, Gubareva LV, Zuccotti G. Prolonged shedding of multidrug-resistant influenza A virus in an immunocompromised patient. N Engl J Med. 2003; 348(9): 867-8.

27. van der Vries E, van den Berg B, Schutten M. Fatal oseltamivir-resistant influenza virus infection. N Engl J Med. 2008; 359(10): 1074-6.

28. Gooskens J, Jonges M, Claas EC, Meijer A, van den Broek PJ, Kroes AM. Morbidity and mortality associated with nosocomial transmission of oseltamivir-resistant influenza $A(H 1 N 1)$ virus. JAMA. 2009; 301(10): 1042-6.

29. Renaud C, Campbell AP. Changing epidemiology of respiratory viral infections in hematopoietic cell transplant recipients and solid organ transplant recipients. Curr Opin Infect Dis. 2011; 24(4): 333-43.

30. Weigt SS, Gregson AL, Deng JC, J.P. Lynch, Belperio JA. Respiratory viral infections in hematopoietic stem cell and solid organ transplant recipients. Semin Respir Crit Care Med. 2011; 32(4): 471-93. 
31. Reid G, Huprikar S, Patel G, Razonable RR, Mossad S, Levi M, et al. A multicenter evaluation of pandemic influenza A/H1N1 in hematopoietic stem cell transplant recipients. Transpl Infect Dis. 2013; 15(5): 487-92.

32. Engelhard D, Mohty B, de la Camara R, Cordonnier C, Ljungman P. European guidelines for prevention and management of influenza in hematopoietic stem cell transplantation and leukemia patients: summary of ECIL-4 (2011), on behalf of ECIL, a joint venture of EBMT, EORTC, ICHS, and ELN. Transpl Infect Dis. 2013; 15(3): 219-32.

33. Choi SM, Boudreault AA, Xie H, Englund JA, Corey L, Boeckh M. Differences in clinical outcomes after 2009 influenza $A / H 1 N 1$ and seasonal influenza among hematopoietic cell transplant recipients.Blood. Blood. 2011; 117(19): 5050-6.

34. Pochon C, Voigt S. Respiratory Virus Infections in Hematopoietic Cell Transplant Recipients. Front Microbiol. 2019; 9: 3294.

35. Machado CM. Influenza infections after hematopoietic stem cell transplantation. Clin Infect Dis. 2005; 41(2): 273-4.

36. Ljungman P. Solid-organ transplants and the risks of pandemic influenza. Lancet Infect Dis. 2010; 10(8): 506-7.

37. Engelhard D, Mohty B, de la Camara R, Cordonnier C, Ljungman P. European guidelines for prevention and management of influenza in hematopoietic stem cell transplantation and leukemia patients: summary of ECIL-4 (2011), on behalf of ECIL, a joint venture of EBMT, EORTC, ICHS, and ELN. Transpl Infect Dis. 2013; 15(3): 219-32.

38. Danzinger-Isakov L, Kumar D; AST Infectious Diseases Community of Practice. Guidelines for vaccination of solid organ transplant candidates and recipients. Am J Transplant. 2009; 9 Suppl 4: S258-62.

39. Cordonnier C, Einarsdottir S, Cesaro S, Di Blasi R, Mikulska M, Rieger C, et al. Vaccination of haemopoietic stem cell transplant recipients: guidelines of the 2017 European Conference on Infections in Leukaemia (ECIL 7). Lancet Infect Dis. 2019; 19(6): e200-e212.

40. Chong PP, Handler L, Weber DJ. A Systematic Review of Safety and Immunogenicity of Influenza Vaccination Strategies in Solid Organ Transplant Recipients. Clin Infect Dis. 2018; 66(11): 18021811.

\section{Figures}




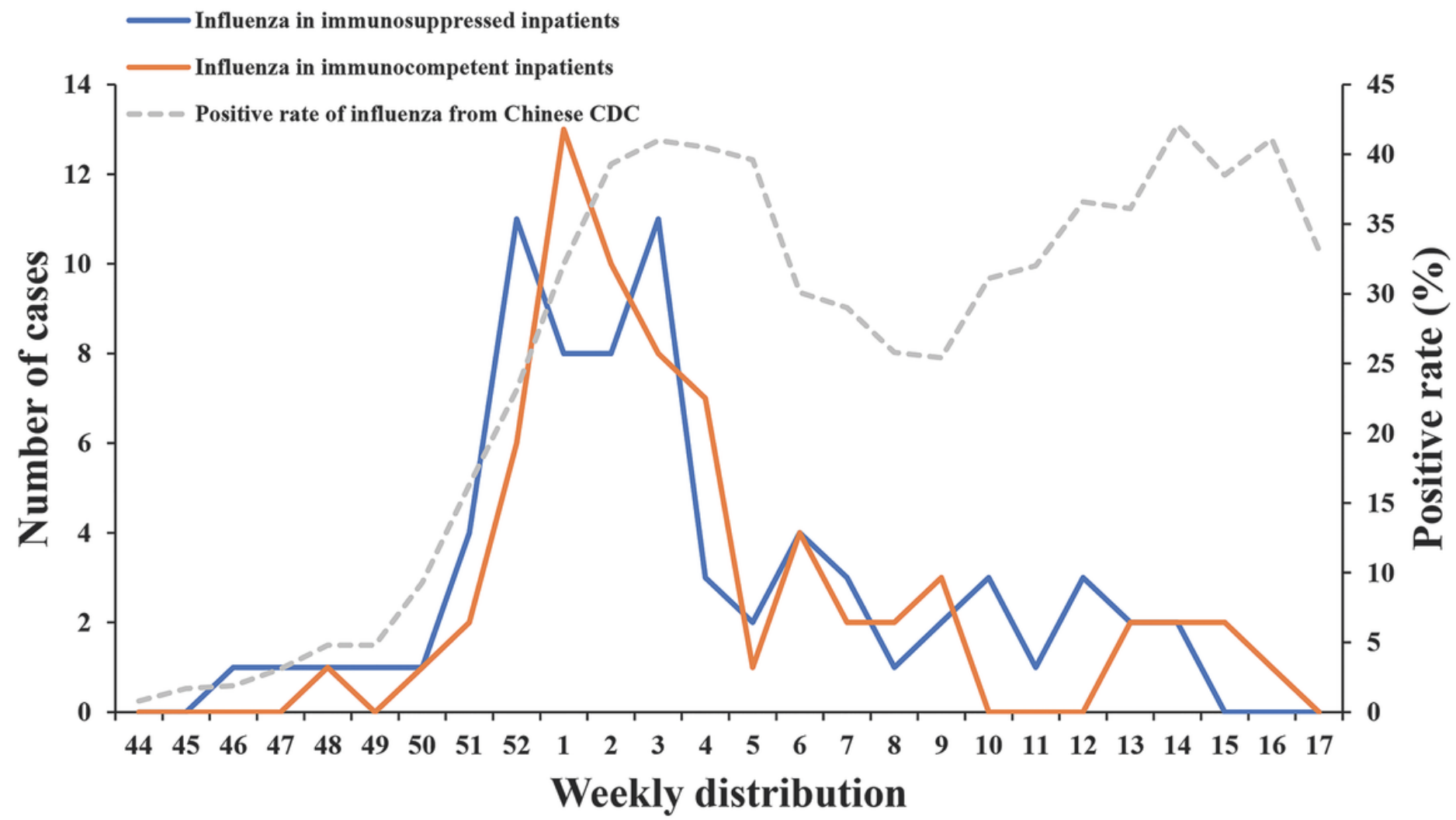

Figure 1

Weekly distribution of symptom onset in immunosuppressed and immunocompetent inpatients in PKUPH. The dotted line represents positive rate of influenza from Chinese Center for Disease Control and Prevention in northern China during November 2018 to April 2019. 


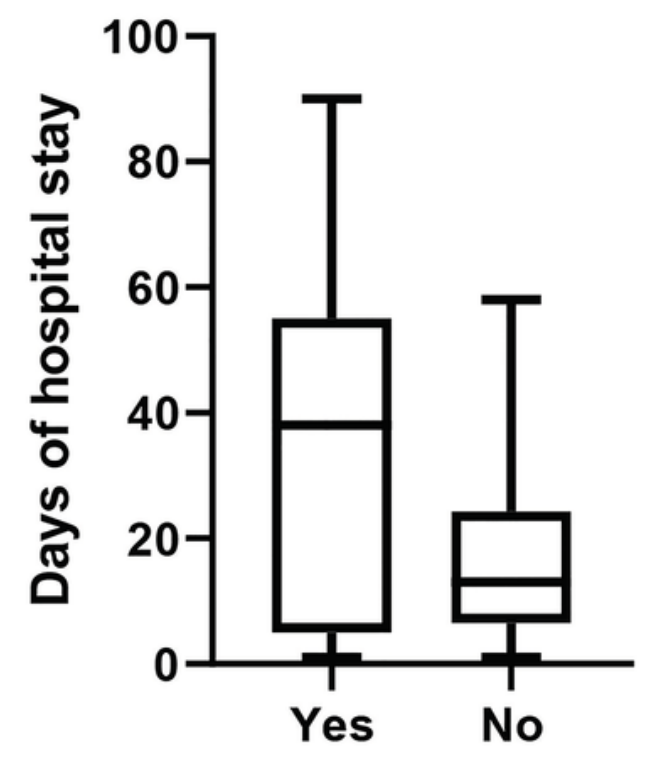

Organ transplantation

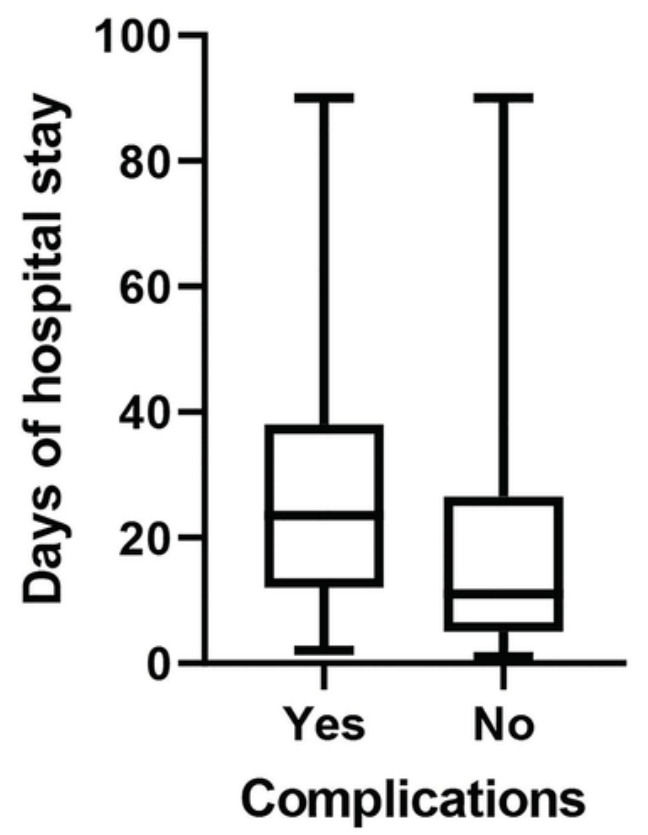

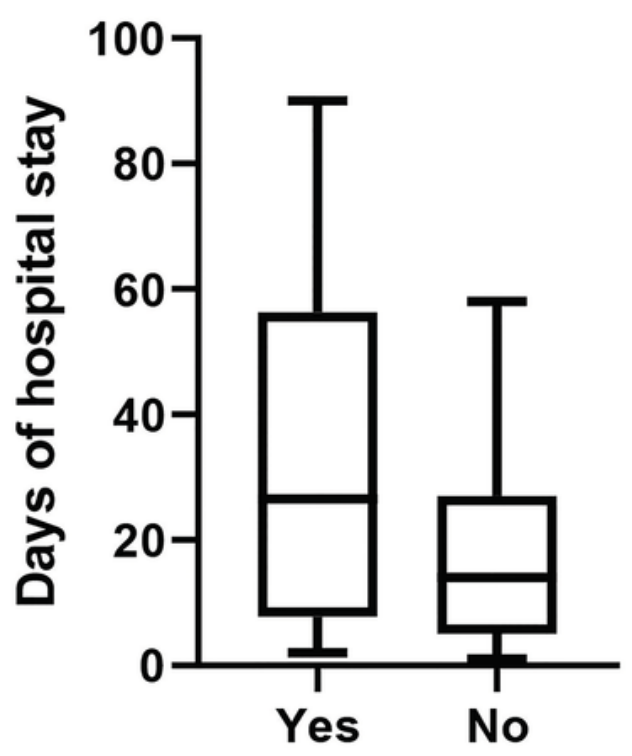

Application of corticosteroids in preceding 3 months

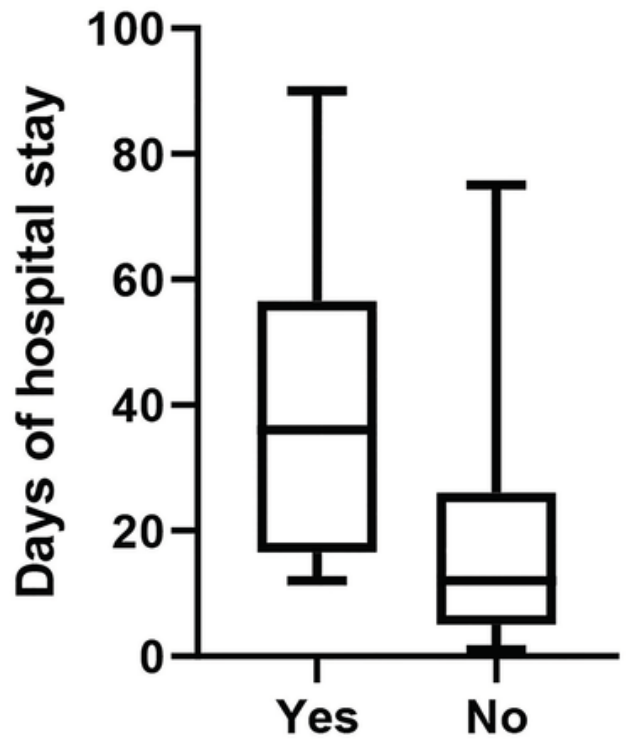

Co-infection with other infections

Figure 2

Box plot of days of hospital stay in immunosuppressed patients with influenza infections. 

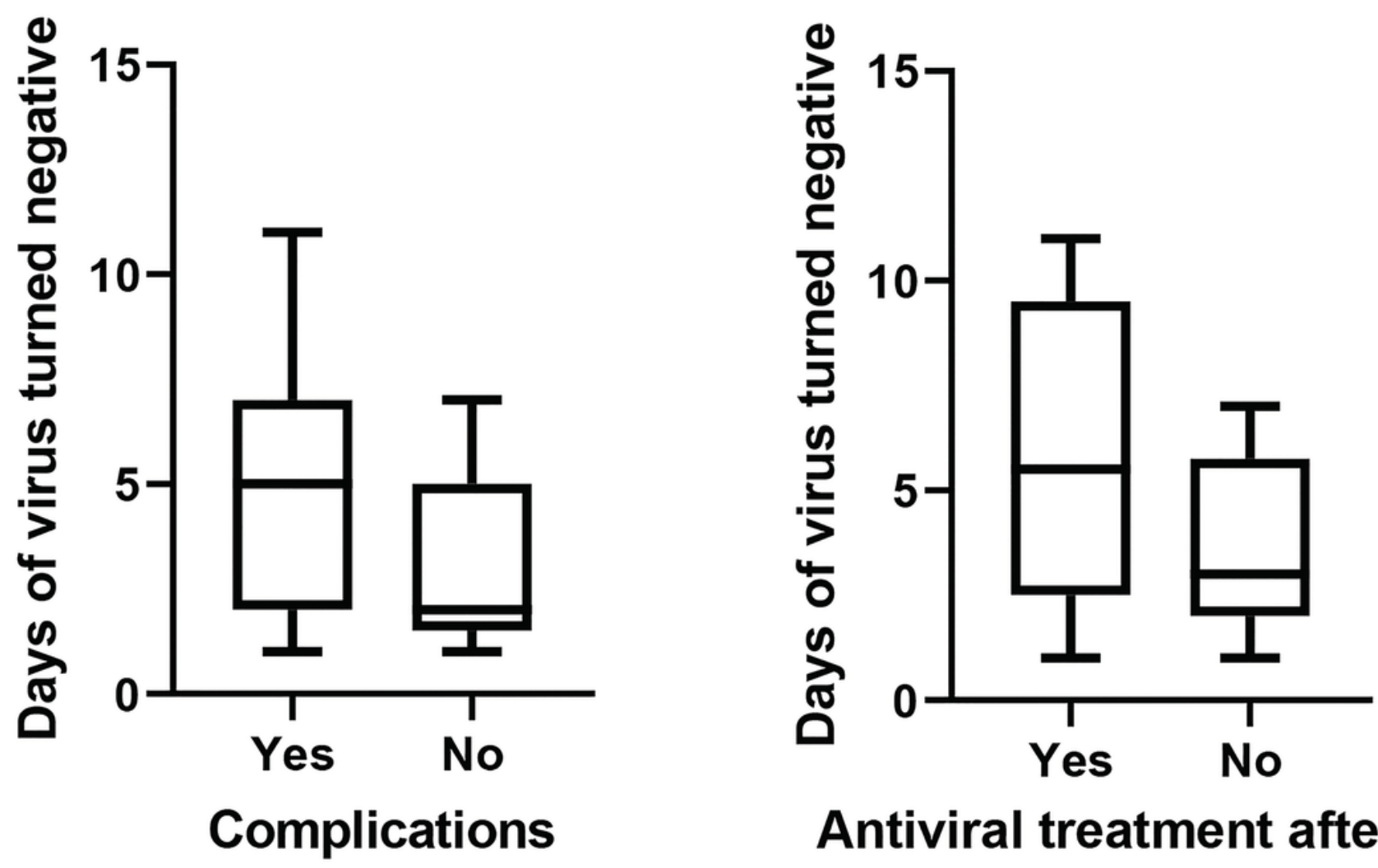

Antiviral treatment after $48 \mathrm{~h}$

Figure 3

Box plot of days of virus detection turned negative in immunosuppressed patients with influenza infections. 